\title{
Correction to: The Role
} of Oxytocin in Early Life Adversity and Later Psychopathology: a Review of Preclinical and Clinical Studies

\section{Amalia Londono Tobon, $M D^{1}$ \\ $D$. Jeffrey Newport, MD, MS, MDiv ${ }^{2}$ \\ Charles B. Nemeroff, $M D, P h D^{3, *}$}

\author{
Address \\ ${ }^{1}$ Department of Psychiatry, Child Study Center, Yale University School of Medicine, \\ New Haven, CT, USA \\ ${ }^{2}$ Departments of Psychiatry \& Behavioral Sciences and Obstetrics \& Gynecology, \\ University of Miami Miller School of Medicine, Miami, FL, USA \\ ${ }^{*}, 3$ Department of Psychiatry, Institute for Early Life Adversity Research, University \\ of Texas at Austin Dell Medical School, Health Discovery Building, 1701 Trinity St., \\ Stop Z0600, Office HDB 2.138, Austin, TX, 78712-1873, USA \\ Email: cnemeroff@austin.utexas.edu
}

Published online: 10 January 2019

(C) Springer Nature Switzerland AG 2019

The online version of the original article can be found at https://doi.org/10.1007/s40501-018-0158-9

Correction to: Curr Treat Options Psychiatry (2018) https://doi.org/10.1007/s40501-018-0158-9

The original publication of this article is missing a disclosure statement for Dr. Amalia Londono Tobon. The disclosure statement for Dr. Londono Tobon should be:

Dr. Londono Tobon reports grants from AACAP, grants from NIMH T32 5T32MH018268-34, grants from Substance Abuse and Mental Health Services Administration - American Psychiatric Association, from Ariella Ritvo Pilot Research Award, outside the submitted work. 